This item was submitted to Loughborough's Research Repository by the author.

Items in Figshare are protected by copyright, with all rights reserved, unless otherwise indicated.

\title{
Improved access to urban water services in Uganda
}

PLEASE CITE THE PUBLISHED VERSION

http://www.municipalengineer.com

\section{PUBLISHER}

(c) Institution of Civil Engineers

VERSION

VoR (Version of Record)

LICENCE

CC BY-NC-ND 4.0

REPOSITORY RECORD

Kayaga, Sam, Julie Fisher, and Richard Franceys. 2019. "Improved Access to Urban Water Services in Uganda". figshare. https://hdl.handle.net/2134/9919. 
This item was submitted to Loughborough's Institutional Repository (https://dspace.lboro.ac.uk/) by the author and is made available under the following Creative Commons Licence conditions.

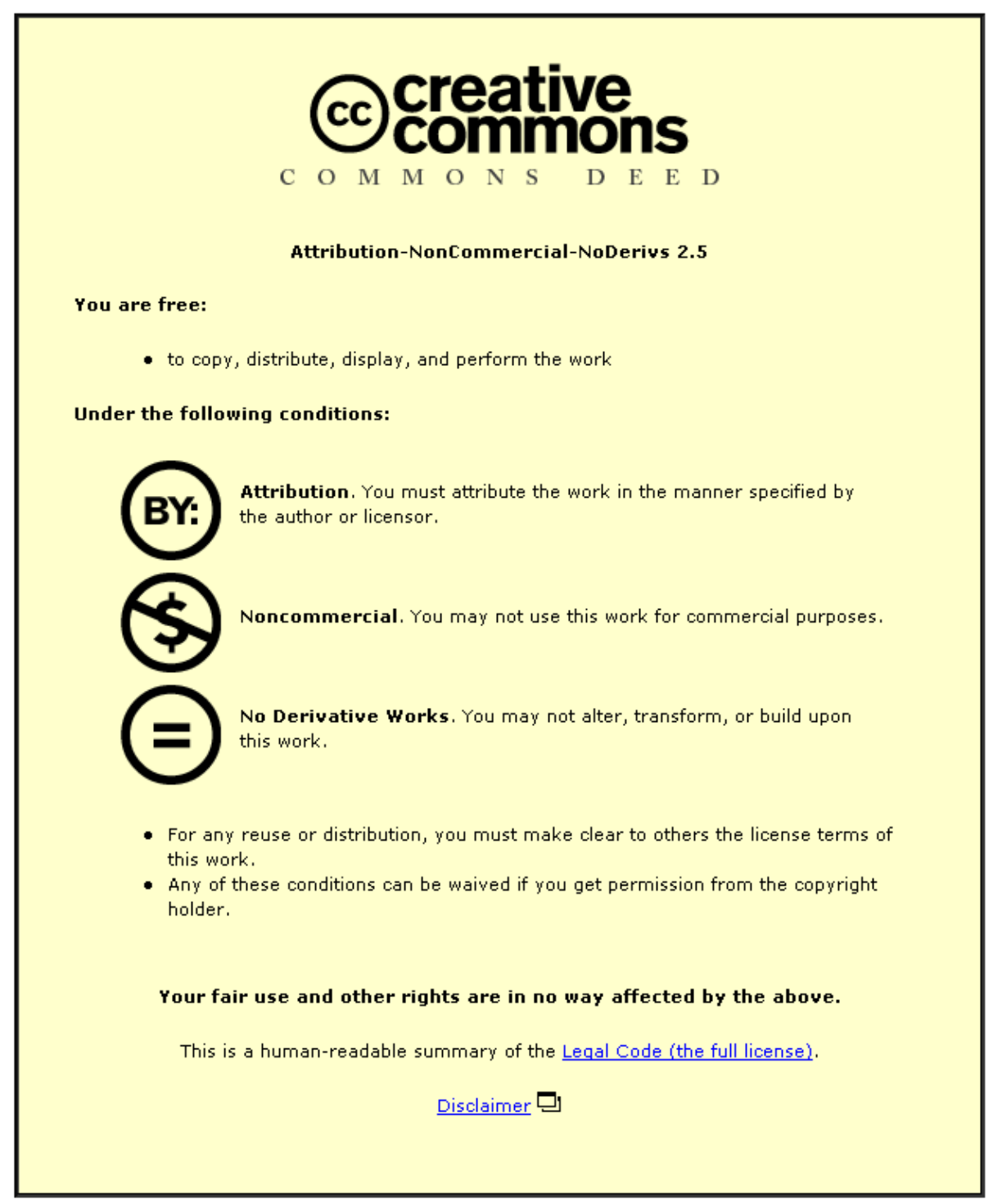

For the full text of this licence, please go to: http://creativecommons.org/licenses/by-nc-nd/2.5/ 

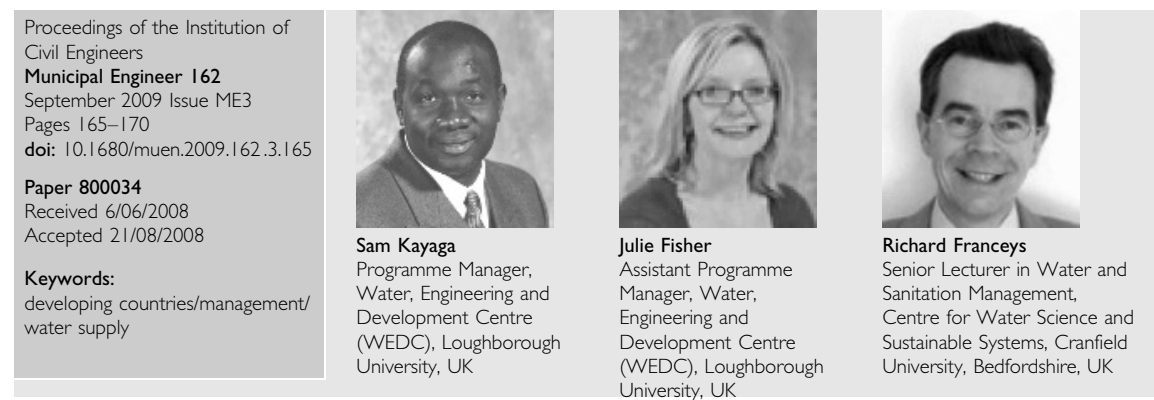

\section{Improved access to urban water services in Uganda}

S. Kayaga MSc, PhD, CEng, MCIWEM, J. Fisher MA, PhD and R. Franceys PhD, MBA, Eur Ing, MICE

According to a 2004 Unicef/World Health Organization assessment, developing countries are more likely to achieve the millennium development goal (MDG) drinking water target in urban than in rural areas. However, this achievement is threatened by a high urbanisation rate in developing countries, where the urban population is projected to increase by about two billion between 2000 and 2030. For instance, although the global urban population with adequate water service levels increased in real terms by $36 \%$ between 1990 and 2004, overall coverage has remained practically unchanged at $95 \%$. Given these high urbanisation rates, water utilities in developing countries need to be innovative in order to improve or maintain service coverage in their service areas. This paper presents the case of the National Water and Sewerage Corporation (NWSC) of Uganda, which has improved service coverage tremendously over the past decade through innovative management. Between 1998 and 2007, NWSC registered the following key performance improvements: number of service connections from 54000 to over 180 000; service coverage from $51 \%$ to $71 \%$ of the population; towns served from 12 to 22 ; billing efficiency from $51 \%$ to $67.5 \%$. The paper describes the specific measures that have contributed to this high performance improvement.

\section{WATER AND SANITATION COVERAGE IN DEVELOPING COUNTRIES}

Since September 2000 when 189 United Nations (UN) member states endorsed the millennium declaration, the eight measurable and time-bound millennium development goals (MDGs) became a universal framework for monitoring development. The MDGs aim to reduce poverty, hunger, disease, illiteracy, environmental degradation and discrimination against women by 2015. One of the targets contributing to the seventh goal on environmental sustainability is to reduce (by half) the proportion of people without sustainable access to safe drinking water and basic sanitation by 2015. Access to safe water and basic sanitation services does not only enhance environmental sustainability. It also has a direct and highly significant influence on the achievement of other MDGs such as goal 1 on the eradication of extreme poverty, goal 2 on the achievement of universal primary education, goal 3 on the promotion of gender equality and empowerment of women, and goal 4 on the reduction of child mortality. ${ }^{1}$
The World Health Organization (WHO) and UN Children's Fund (Unicef) joint monitoring programme for water and sanitationresponsible for evaluating progress towards achievement of the target-monitors the proportion of the population using improved drinking water sources and sanitation facilities. This information is compiled from national censuses and nationally representative samples such as demographic and health surveys, world health surveys and multiple-indicator cluster surveys. Improved drinking water sources include: piped water into dwelling plot or yard; public tap or standpipe; tube well or borehole; protected dug well; protected spring; and rainwater collection. Improved sanitation facilities include: flush or pourflush to piped sewer system, septic tank or pit latrine; ventilated improved pit latrine; pit latrine with slab; and composting toilet. $^{2}$

The 2004 assessment of progress towards achievement of the MDG target for water and sanitation services shows that, although global progress has been made since 1990, national governments in many developing countries need to increase their effort in order to achieve the desired targets. ${ }^{2,3}$ The assessment noted that while 1.2 billion people gained access to both safe drinking water and improved sanitation from 1990 to 2004, if the MDG targets are to be achieved, access to improved sanitation and water supply needs to be provided to a further 1.6 billion and $1 \cdot 1$ billion people respectively between 2005 and 2015. In terms of numbers, this translates into providing improved water and sanitation services to an additional 450000 and 300000 people respectively every day over the same time period. ${ }^{2}$ Business as usual will not lead to achievement of the target. Reaching these targets will require the doubling of current efforts for sanitation and stepping up improvements in drinking water supply by about a third. ${ }^{2}$

About $80 \%$ of the un-served population live in sub-Saharan Africa, eastern Asia and southern Asia. However, the global statistics presented in the relevant literature often mask the high disparity that exists between different regions of the developing world. For instance, whereas water supply coverage is above 78\% in eastern and southern Asia, access in sub-Saharan Africa is about $56 \% .^{2}$ Even within sub-Saharan Africa, access to water and sanitation services differs from one country to another. For instance, in 2004 some sub-Saharan countries had drinking water service coverage of at least 75\% (Botswana (95\%), Burkina Faso (82\%), Burundi (79\%), Central African Republic (75\%), Chad (75\%), Gabon (88\%), Gambia (82\%), Ghana (75\%), Lesotho 
(79\%), Senegal (76\%) and Zimbabwe (81\%)), while others had 2004 coverage rates below 50\% (e.g. Chad (42\%), Democratic Republic of Congo (46\%), Equatorial Guinea (43\%), Ethiopia (22\%), Mozambique (43\%), Niger (46\%) and Nigeria (48\%)). ${ }^{2}$

The sanitation picture in sub-Saharan Africa is even worse, with an overall service coverage of $37 \%{ }^{2}$ Sub-Saharan countries with dismal 2004 sanitation service coverage of less than 30\% include Burkina Faso (13\%), Central African Republic (27\%), Chad (9\%), Congo (27\%), Ethiopia (13\%), Ghana (18\%), Guinea $(18 \%)$, Liberia $(27 \%)$ and Niger $(13 \%) .^{2}$ There is also a category of countries where national sanitation coverage lags far behind that for water supply. Typical examples where sanitation service coverage figures are less than half those for water are shown in Table $1 .^{2}$ Clearly, more efforts are required to understand how the sanitation gap could best be closed.

Another issue of concern is the disparity in service levels between rural and urban areas. Access to safe drinking water is significantly higher in urban than rural areas in the developing regions-in sub-Saharan Africa in 2004, service coverage was estimated at $80 \%$ in urban areas and only $42 \%$ in rural regions. ${ }^{2}$ Similar disparities occur for sanitation coverage. Whereas access to safe sanitation service levels in urban areas in sub-Saharan Africa was estimated at 53\% in 2004, rural sanitation coverage was only $28 \% .^{2}$ However, these trends are bound to change as urban areas in developing countries experience rapid population increases due to a combination of rural-urban migration and national population growth rates. For instance, the global urban population is projected to increase by about $2 \cdot 12$ billion between 2000 and 2030, with over 95\% (about two billion people) of this increase expected to be in low-income countries. ${ }^{4}$

It is evident that rural areas lag behind urban areas as far as water and sanitation coverage is concerned. However, the rapid urbanisation rates in developing countries present different challenges. For instance, although an extra 772 million people gained access to safe drinking water between 1990 and 2004 (an increase of $36 \%$ in real terms), the overall population coverage has remained practically unchanged at 95\%. ${ }^{2}$ Further analysis of national data shows that 22 countries, nine of which are situated in sub-Saharan Africa, suffered a decline in urban drinking water coverage over this period. ${ }^{2}$

\begin{tabular}{|lcc|}
\hline & \multicolumn{2}{c|}{ Service coverage: \% } \\
\cline { 2 - 3 } & Water & Sanitation \\
\hline Botswana & 95 & 42 \\
Burkina Faso & 61 & 13 \\
Burundi & 79 & 36 \\
Central African Republic & 75 & 27 \\
Gabon & 75 & 18 \\
Lesotho & 79 & 37 \\
Liberia & 61 & 27 \\
Madagascar & 77 & 32 \\
Niger & 46 & 13 \\
Sudan & 70 & 34 \\
\hline
\end{tabular}

Table I. Discrepancies in water and sanitation supply in sub-Saharan countries
Apart from rapid urbanisation rates, another key challenge for urban water utilities in developing countries is the fact that most of the urban population growth is being absorbed into slums. For instance, in sub-Saharan Africa, 62\% of urban dwellers in 2005 lived in slum conditions, providing additional barriers for extending water services to these residents. ${ }^{4}$ Clearly, urban water utilities in developing countries need to be innovative in order to improve or maintain coverage in their service areas. This paper discusses the challenges caused by varying definitions of access to water services, describes how access is measured in Uganda and presents the case of the National Water and Sewerage Corporation (NWSC) of Uganda which, through innovative management solutions, has made tremendous advances in improving access to piped water supply over the past decade.

\section{HOW IS ACCESS TO WATER SERVICES DEFINED?}

One practical problem associated with monitoring MDGs is the lack of harmonisation of definitions and concepts not only in different countries but also within different sectors and institutions of the same country. Access and usage are terms that are usually used interchangeably to describe whether safe and reliable water sources are located in places where they can be and are used. The sources should provide adequate quantities of adequate quality of water in a convenient way. ${ }^{5}$ However, the constructs of convenience and adequate quantity are difficult to quantify as they lack clear measurable outcomes.

Furthermore, assessing the quality of water at household level is not only expensive, but can also be complicated-especially in cases where households use multiple sources of water. For this reason, the type of water source is usually used as a proxy indicator for water quality. Where usage can accurately be measured, this is a better indicator of access, as the benefits from a water supply can only accrue when water sources are used. However, coverage of water supply for achieving global targets is more commonly monitored in terms of access rather than usage, mainly because service providers can more easily be held responsible for access. ${ }^{5}$

Historically, the most frequently used definition of water supply coverage is that of the UN Development Programme (UNDP). It states that those with access comprise the proportion of the population using any of the following 'improved' water sources: piped water; public tap; borehole with a pump; protected well; springs; or rainwater. ${ }^{6}$ Essentially, technology is used as an indication of improved water supply. ${ }^{7}$ The World Bank $^{8}$ specifies further: in urban areas a safe water source should be located not more than $200 \mathrm{~m}$ away; in rural areas access implies that householders should not spend a disproportionate part of the day fetching water. The latter definition is grossly lacking for rural areas as it does not specify what constitutes a 'disproportionate part of the day'. Neither is there a global consensus on the criteria used to calculate the 'proportion of the population'. 9

An awareness of these deficiencies has led some countries to modify definitions to derive indicators for monitoring the MDG target on drinking water supply. Three factors have been variously used to formulate country-specific definitionsdistance, time and water quantity. A review of 45 countries 


\begin{tabular}{|c|c|c|c|}
\hline \multirow[b]{2}{*}{ Indicator } & \multirow[b]{2}{*}{ Classification } & \multicolumn{2}{|c|}{ Number of countries } \\
\hline & & Urban areas & Rural areas \\
\hline Distance from safe water source: $m$ & $\begin{array}{r}<50 \\
<100 \\
<250 \\
<500 \\
<1000 \\
<2000\end{array}$ & $\begin{array}{r}20 \\
5 \\
2 \\
3 \\
1 \\
0\end{array}$ & $\begin{array}{r}10 \\
1 \\
6 \\
17 \\
4 \\
4\end{array}$ \\
\hline Quantity of safe water available: I/day per person & $\begin{array}{r}15-20 \\
20 \\
20-30 \\
30-50 \\
>50\end{array}$ & $\begin{array}{r}0 \\
0 \\
0 \\
0 \\
33\end{array}$ & $\begin{array}{r}1 \\
19 \\
5 \\
10 \\
3\end{array}$ \\
\hline Time to travel to safe water source: $\min$ & $\begin{array}{r}5 \\
15 \\
30\end{array}$ & $\begin{array}{l}1 \\
0 \\
1\end{array}$ & $\begin{array}{l}0 \\
1 \\
1\end{array}$ \\
\hline
\end{tabular}

jointly carried out by WHO and Unicef in 1996 showed that 42 countries used distance-based definitions, 38 used definitions based on water quantity, two used time-based definitions and 37 countries defined access using a combination of the three indicators. Table 2 lists a breakdown of the findings of this assessment. The table shows that different countries are using various targets with disparate ranges for tracking MDGs, which emphasises the fact that global statistics can provide only an approximation of water supply coverage. It also shows that most countries have adopted multi-dimensional indicators to accurately define access.

\section{CURRENT URBAN WATER SERVICE COVERAGE IN UGANDA}

The means of monitoring service coverage to achieve the MDG target for drinking water supply in Uganda is similar to that used in other developing countries. In 2003 in Uganda-a subSaharan country with a population estimated at 26.9 million$55 \%$ of people were living below the national poverty line. ${ }^{10}$ Water supply services to rural and small towns (i.e. populations of 5000-15 000) is the responsibility of the Directorate of Water Development (DWD) (the lead government agency in the water/sanitation sector in Uganda), with operation and maintenance functions delegated to local governments. Urban areas with populations of over 15000 are usually handed over to NWSC, a government-owned corporate water utility. In 2006, NWSC provided water and sewerage services to 18 urban areas in Uganda with a total estimated population of about $2 \cdot 4$ million people. ${ }^{11}$ Since then, 150 urban areas (total population $2 \cdot 3$ million) have been categorised as small towns and consequently the number of towns transferred to NWSC has risen to $22 .{ }^{10,12}$

A sector-wide approach to policy-making, planning and budgeting adopted by the Uganda water and sanitation sector in 2001 led to harmonisation of monitoring and evaluation of performance in the sector. ${ }^{13,14} \mathrm{~A}$ demand-led performance measurement framework was developed in 2003 that

(a) harmonised definitions, concepts and objectives across sector institutions (b) prioritised indicators and targets based on key performance themes

(c) allocated roles and responsibilities for data collection, analysis, distribution and use. ${ }^{13,14}$

Based on this framework, monitoring and evaluation of urban water service coverage has not only become qualitatively better, but has also been harmonised across the sector institutions. ${ }^{13}$ Prior to 2006, the method used for computing urban water coverage in small towns managed by the DWD differed from that used in larger towns managed by NWSC. Coverage in small towns was computed based on the count of improved water points multiplied by an assumed number of people using the source (eight for a household connection, 32 for a yard tap, 200 for a protected shallow well and 300 for each of public standpipe, shallow well and borehole). On the other hand, NWSC based its estimate on the volume of water billed to households divided by an assumed average per capita of $60 \mathrm{l} /$ day. ${ }^{15}$

These methods were deemed to be not only fragmented but also grossly inaccurate. Consequently, since 2006 the methods used by DWD and NWSC for computing water service coverage have been harmonised. Data are obtained from Uganda Bureau of Statistics on the most recent household size and access is computed based on the assumption that a household connection serves six people, yard taps supply 24 people (four households) and a public stand pipe, deep borehole or protected spring serves 150 people (25 households). ${ }^{11}$ However, in compiling the Uganda water and sanitation sector performance report, it was assumed that boreholes and protected springs in the larger towns serviced by NWSC do not provide potable water supply, probably due to the higher risks of groundwater contamination in highly urbanised areas. Based on these assumptions, service coverage in small towns in 2006 was estimated at 31\% (22\% with access to piped water supply and $9 \%$ with access to protected springs and boreholes). ${ }^{11}$ On the other hand, piped water supply service coverage in larger towns was computed to be $70 \%$ in 2006 , an increase from $48 \%$ in $1998 .{ }^{11,16}$ The overall urban water service coverage was estimated to be about 65\% in 2006. ${ }^{11}$ The next section 
highlights initiatives undertaken by NWSC to improve service coverage in larger towns.

\section{INCREASING WATER SUPPLY COVERAGE BY NWSC}

\section{I. NWSC at the turn of the millennium}

NWSC, the major urban utility in Uganda, was established under Decree 34 in 1972 by the military government of the day, initially to provide water and sewerage services to the country's three biggest towns of Kampala, Jinja and Entebbe. Although it was established to be an autonomous self-sustaining public utility, NWSC's organisational and financing appendage to the central government remained intact in its early years of operation. NWSC's legal status was strengthened by the NWSC Statute No. 7 of 1995 and the NWSC Act of 2000, which have made NWSC more autonomous. In the late 1990s, as NWSC expanded its geographical coverage by adding nine more towns to its portfolio, the utility experienced financial deficits as a result of four main factors.

(a) NWSC was expected to service the loans that financed the reconstruction and expansion of the infrastructure in the newly acquired towns.

(b) Compared with the three nucleus towns of Kampala, Jinja and Entebbe, the newly acquired towns were smaller in size, which eroded benefits from economies of scale.

(c) Less economic activities in the small towns meant that customers in the new service areas generally had a lower ability and willingness to pay for improved service levels.

(d) NWSC continued to be managed largely as an engineeringled organisation, oblivious to the changes in the internal and external environment that required a shift towards market orientation.

The production-orientation management philosophy espoused by NWSC, coupled with poor operational and financial performance during the utility's expansion phase, had a significant impact on service coverage. More capital funding was committed to the easier engineering-designed water treatment plants and trunk distribution main pipes at the expense of extension of tertiary and service pipelines. As a result, access to piped water supply services remained low in spite of the overall large capital investments committed to the urban water sub-sector. For instance, Lira water supply service area (a town with a population of 90000 in 2002) had piped water supply coverage of 56\% in 2003, utilising only 19\% of the water treatment capacity that was installed ten years earlier. ${ }^{17}$ This mismatch in infrastructure development mainly affects the urban poor living in multi-occupancy tenements or compounds of slums, shanties, unplanned and illegal settlements; they usually pay ten to 20 times more per cubic metre of water than people living in planned residences connected to the distribution network. ${ }^{18}$ The key barrier for the urban poor to connect to the utility network is the long distances (usually several hundreds of metres) through which households are expected to extend their service lines-an expenditure not affordable for many households. ${ }^{18,19}$ It is not surprising therefore that, by 1998, NWSC had only about 51000 properties connected to water supply systems in 12 serviced towns, 37\% of which had been temporarily disconnected mainly due to non-payment of water bills. ${ }^{16,20}$
Using the method described in Section 3, service coverage in these towns was estimated to be $48 \%$ in $1998 .^{16,20}$

\subsection{Measures for increasing service coverage}

The organisational performance of NWSC continued to deteriorate in the late 1990s, despite the engagement of an international operator on a two-year contract to manage water distribution, billing and revenue collection for the Kampala water supply area, the utility's cash cow. ${ }^{12}$ In response, the government of Uganda changed the board of directors and, in 1998, appointed a new managing director who initiated an ongoing change management programme aimed at turning round the overall performance of the utility. ${ }^{16}$ The programme seeks to apply new public management (NPM) concepts that aim to reform public sector organisations by cloning managerial practices from the private sector. The key principles underpinning NPM are ${ }^{21}$

(a) hands-on professional management

(b) explicit standards and measures of performance

(c) greater emphasis on output controls

(d) decentralisation of service delivery

(e) shift to greater competition

$(f)$ the use of private sector styles of management practice

(g) greater emphasis on discipline and parsimony in resource use.

In adapting NPM principles to the local operating environment, NWSC's change management programme aimed at transforming the public utility through application of private sector management principles and turning around its declining performance. ${ }^{16,20}$ In the internal environment, the newly appointed managing director and the existing management team designed and implemented a series of short-term internal performance improvement programmes that aimed to reverse the decline in financial and operational performance trends and restore customer confidence. These programmes, which have been adequately described in other articles, include the 100-day and service revenue enhancement programmes (1999-2000), internal area performance management contracts (2000-2003) and internally delegated area management contracts (from 2003 and ongoing). ${ }^{12,16,20}$ In the external environment, the leadership of NWSC moved fast to enhance its level of organisational autonomy and solicited for political support that was critical in striking a delicate balance between the political and financial objectives of the organisation. ${ }^{22,23}$ A key focus area of the change management programme is expansion of the customer base in order to increase access to piped water services and improve service coverage. ${ }^{16,20}$

Many initiatives undertaken as part of the change management programme made a significant contribution to improving access to piped water supply networks. The activities that directly contributed to improved access and service coverage are as follows.

(a) Some water supply areas experienced long-standing technical bottlenecks in water treatment processes, the most common ones being inadequate filtration and pumping capacities. Defects arising from inadequate operational processes and maintenance procedures were corrected, resulting in an increase in overall plant capacity utilisation from $58 \%$ in 1998 to $73 \%$ in $2006 .^{24,25}$ 
(b) Gross water supplied to customers by NWSC increased from $127000 \mathrm{~m}^{3} /$ day in 1998 to $166200 \mathrm{~m}^{3}$ /day (an increase of about $30 \%$ ) in $2007 .^{24,26}$

(c) Geographical expansion has seen areas serviced by NWSC increase from 11 towns with a total potential demand of about one million people in 1998 to 22 towns with a target population of about $1 \cdot 8$ million people in $2007 .^{24,26}$

(d) The water reticulation network has been extended from $1633 \mathrm{~km}$ at the turn of the century to 3206 kilometres in 2007, representing an increase of about 95\%. ${ }^{24,26}$

(e) Through strategies to improve active leak detection, speed of repairs and replacement of aged pipelines, non-revenue water has been reduced from $49 \%$ in 1998 to $31.5 \%$ in June 2007. ${ }^{24,26}$ These strategies have freed up a substantial quantity of supply for legitimate consumption.

( $f$ ) A study on the tariff structure carried out by an independent consultant reported that the high connection fee was a barrier for low- and middle-income households to gain access to the piped water system, minimum charges were a disincentive to water saving and the prohibitive reconnection fee (in the event of disconnection due to non-payment of bills) was a deterrent to customers' willingness to reconnect to the system. Based on the consultant's recommendations, connection fees were reduced by $50 \%$, reconnection fees by $74 \%$ and minimum charges were replaced by smaller service charges in 2001. ${ }^{27}$

(g) NWSC participated in an international research project sponsored by the UK Department for International Development (DFID) into 'barriers of entry to piped water supply by the urban poor'. The project found that, in 2003, customers in Uganda spent a mean of US\$ 500 to gain access to NWSC's water supply system. ${ }^{18,19}$ Informed by these findings, NWSC's new-connection policy was reviewed in July 2004 to simplify procedures and provide subsidies for access. Subsequently, customers now pay a connection fee of 50000 Uganda shillings (US\$28) while NWSC pays all the connection costs (i.e. pipes, fittings and labour) up to a maximum distance of $50 \mathrm{~m}$ from the tertiary main. ${ }^{27}$

(h) NWSC has commissioned a pilot study in Kampala to investigate how households living in low-income settlements could be best serviced. The project is trialling various service options, for example partnerships with communities, partnerships with informal small-scale service providers, household on-selling and prepaid meters. ${ }^{26}$

(i) NWSC has set up a unit dedicated to providing services to low-income households living in informal settlements. This unit, which is already operating in Kampala, works with communities and local small-scale entrepreneurs to find solutions for effective service provision to unplanned settlements. $^{26}$

These measures have obviously resulted in improved access to urban water supply services in Uganda. The number of customer connections has increased from 55885 in June 1998 to 180697 in June 2007. ${ }^{25}$ This overall figure includes 5314 public standpipes installed in low-income settlements for enhancement of services to the urban poor. ${ }^{25}$ Based on the criteria approved by the Uganda water/sanitation sector performance measurement taskforce and discussed in Section 3, the total population now serviced by NWSC is about 1.79 million; for a target population of 2.54 million, this gives a service coverage of $70 \% .{ }^{11,25}$ The number of active accounts (i.e. those properties that are not temporarily disconnected due to non-payment or other reasons) gives a proxy indicator for usage, which is a better performance measure of access. NWSC's initiatives have increased the proportion of active accounts from 60\% in 1998 to about $88 \%$ in $2006 .^{12}$

It is important to note that NWSC's measures were successfully implemented because key favourable events took place in both external and internal environments. Externally, the government of Uganda initiated a reform process aimed at increasing separation of roles between central government and the utility, thus increasing the service provider's autonomy and enhancing external accountability. ${ }^{22}$ In the internal environment, the previous leadership of the utility had invested heavily in developing the technical and managerial capacity of staff, to the extent that by the turn of the century most senior and middle managers at NWSC held postgraduate qualifications in various disciplines. The high calibre of staff enabled managers to effectively scan the external/internal environments, leverage their strengths, minimise weaknesses, capitalise on opportunities and deter potentially devastating threats. The emergence of strong leadership at the helm of the organisation in the late 1990s more effectively fostered social relationships among the highly professional staff, resulting in enhanced group functioning.

\section{SUMMARY AND CONCLUSIONS}

Sub-Saharan Africa lags behind some other countries in terms of achievement of MDG targets on water supply and sanitation coverage. The situation in the urban sub-sector is being aggravated by rapid urbanisation with the biggest proportion of the population increase being absorbed by unplanned low-income settlements. The case of Uganda's urban water sub-sector provides a typical example. Water service coverage in Uganda's small towns in 2006 was estimated at 31\%, composed of 22\% with access to piped water supply and 9\% with access to protected springs or boreholes. ${ }^{11}$ In larger towns, piped water supply coverage rose from $48 \%$ to $70 \%$ during 1998 to $2006 .{ }^{11,16}$ This means that in terms of meeting the MDG target for drinking water, Uganda has made substantial progress in the urban water subsector, with overall urban water service coverage estimated at 65\%. ${ }^{11}$ However, like many other urban areas in developing countries, this achievement could be eroded by rapid urbanisation. Although in 2005 only 14\% of the population in Uganda lived in urban areas, the urban population growth rate in 2000-2005 was estimated at $5 \cdot 7 \%$ and this is expected to increase, thus resulting in a need for accelerated service coverage. ${ }^{4}$ A proposed solution is the use of innovative managerial approaches not only to maintain high service coverage in planned areas, but also to extend services to unplanned, low-income settlements where water service provision is challenging. The efficacy of this approach has been demonstrated by Uganda's NWSC, a corporate urban water utility that has made great strides in extending service coverage over the past decade. Table 3 shows a detailed summary of key quantitatively verifiable performance indicators that have significantly contributed to Uganda's increase in service coverage.

This case study has shown that increasing coverage of water services requires integrated activities in various departments in order to overcome both physical and 'soft' barriers to sustainable access. NWSC was able to achieve performance improvements through a change management programme in which all departments fully participated. New public management (NPM) 


\begin{tabular}{|lrc|}
\hline & \multicolumn{2}{c|}{ Performance levels } \\
\hline Attribute & 1998 & 2007 \\
\hline Number of towns served & 11 & 22 \\
Target population: million people & $1 \cdot 79$ & $2 \cdot 54$ \\
Gross water produced: $\mathrm{m}^{3} /$ day & 127000 & 200 \\
Capacity utilisation of treatment plants: \% & 58 & 73 \\
Non-revenue water: $\%$ & 1633 & $31 \cdot 5$ \\
Length of reticulation network: km & 55885 & 3206 \\
Number of customer connections & 66 & 897 \\
Connections using water services: $\%$ & 88 \\
\hline Table 3. Key objectively verifiable indicators that have contributed to improved service coverage by NWSC, Uganda
\end{tabular}

concepts and private sector management principles were applied to both internal and external environments, transforming NWSC's operational and financial performance and resulting in increased access to piped water services. Implementation of these change management initiatives was made possible because of an enabling environment created through institutional reforms, accelerated capacity development of staff and strong corporate leadership.

\section{REFERENCES}

1. World Health Organisation and United Nations Children's FunD. Meeting the MDG Drinking Water and Sanitation Target: A Mid-Term Assessment of Progress. WHO/Unicef, Geneva, 2004.

2. World Health Organisation and United Nations Children’s Fund. Meeting the MDG Drinking Water and Sanitation Target: The Urban and Rural Challenge of the Decade. WHO/ Unicef, Geneva, 2006.

3. United Nations. The Millennium Development Goals Report 2007. UN, New York, 2007.

4. UN-Habitat. State of the World's Cities, 2004/05. UNHabitat, Nairobi, 2004.

5. Bostoen K. Monitoring of Water Supply Coverage. Loughborough University, Loughborough, 2005, WELL fact sheet.

6. United Nations Development Programme. Human Development Report. Oxford University Press, New York, 2002.

7. World Health ORganisation and United Nations Children's Fund. Global Water Supply and Sanitation Assessment2000 Report. WHO/Unicef, Geneva, 2000.

8. WorLd BANK. World Development Report 1997. Oxford University Press, New York, 1997.

9. Aiga H. and UMENAI T. Standardisation of the definition of access to safe water. The Lancet, 2003, 361, No. 9375, 2156.

10. United Nations Development Programme (UNDP). Human Development Report 20 - International Cooperation at a crossroads: Aid, Trade and Security in an Unequal World. UNDP, New York, 2005.

11. Government of Uganda. Water and Sanitation Sector Performance Report 2006. Ministry of Water and Environment, Kampala, 2006.

12. Mugisha S., Marin P., Muhairwe S. and Mugabi J. Transforming Public Water Utilities through Private Sectorlike Management Principles: The National Water and Sewerage Corporation, Uganda Experience. World Bank,
Washington, DC, Water Sector Board Discussion Paper (to be published).

13. Kayaga S. Soft systems methodology for performance measurement in the Uganda water sector. Water Policy, 2008, 10, No. 3, 273-284.

14. Thomson M., OKuni P. and SAnsom K. Sector performance reporting in Uganda-from measurement to monitoring to management. Proceedings of 31 st WEDC International Conference, Loughborough, 2006, 130-137.

15. GOVERnMENT OF UgANDA. Water and Sanitation Sector Performance Report 2005. Ministry of Water and Environment, Kampala, 2005.

16. Berg S. V. and MuHAirwe W. T. Healing an Organisation: High Performance Lessons from Africa. University of Florida, USA, 2007, Department of Economics, Public Utility Research Centre (PURC) Working Paper 06-32.

17. National Water and Sewerage Corporation. Annual Report 2002/2003. NWSC, Kampala, 2003.

18. FrAnCEYS R. Charging to enter the water shop? The costs of urban water connections for the poor. Water Science and Technology: Water Supply, 2005, 5, No. 6, 209-216.

19. Kayaga S. and Franceys R. Costs of urban utility water connections: excessive burden to the poor. Utilities Policy, 2007, 15, No. 3, 270-277.

20. Mugisha S. and Berg S. Struggling State-Owned Enterprises: NWSC's Turnaround in Uganda. University of Florida, USA, 2007, Department of Economics, Public Utility Research Centre (PURC) Working Paper 06-36.

21. Brown K., Waterhouse J. and Flynn C. Change management practices: is a hybrid model a better alternative for public sector agencies? The International Journal of Public Sector Management, 2003, 16, No. 3, 230-241.

22. Baietti A., Kingdom B. and Van GinneKen M. Characteristics of Well-performing Public Utilities. World Bank, Washington, DC, 2006, Water Supply and Sanitation Working Paper 9.

23. Schwartz K. The new public management: the future for reforms in the African water supply and sanitation sector? Utilities Policy, 2007, 16, No. 1, 49-58.

24. National Water and Sewerage Corporation. The 100-Days Programme to Improve NWSC Services. NWSC, Kampala, 1999.

25. National Water and SeWerage Corporation. Annual Report 2005/2006. NWSC, Kampala, 2006.

26. National Water and Sewerage Corporation. Annual Report 2006/2007. NWSC, Kampala, 2007.

27. IsINGOMA D. Linking tariff structure changes to improved utility performance in Uganda. In Water Utility 21. IWA Publishing, London, 2005. 